\title{
Computer Use in LMED 100, How to Use the Library
}

\author{
Glenn J. Thompson \\ Chairman, Department of Library Science \\ and Media Education \\ University of Wisconsin \\ Eau Claire
}

In 1971 the Department of Library Science and Media Education at the University of WisconsinEau Claire was asked to develop an undergraduate course for library orientation. LMED 100, How to Use the Library, was developed and first taught in 1972 in response to this request. It was a 2 -credit course with a conventional, classroom-oriented format. LMED 100 was changed to independent study in 1975 to allow for larger enrollments and better to accommodate students' schedules. As enrollments increased through the 1970s, so also did pressures on the instructor and the staff and resources of the MacIntyre Library. In 1981 enrollments were limited to 200 students each semester in an effort to keep the course manageable. During this period, a simplified program for computerassisted instruction was used to offer several programs on the university's mainframe, a Honeywell DPS- 8 computer. This program, named PLANIT, proved to be quite effective; however, reserved characters, a lack of upper and lower case letters and limited capacity for student records did cause problems.

LMED 100 was reorganized in 1983. It was reduced to 1 credit and computer-assisted instruction was used to a greater degree. The revised structure permitted increased enrollments; in fact, no limits were established. PLANIT programs were rewritten in BASIC to permit the use of special characters, to provide for both upper and and lower-case letters, to increase accessibility and to reduce required maintenance. Also, BASIC programs could be downloaded and run on IBM Personal Computers.

At the time of this writing, BASIC programs include the Course Outline and programs providing background information for assignments dealing with the card catalog and the periodical collection. All programs are branching and require interaction. They are available through the mainframe and also on disks for use with IBM Personal Computers in the School of Education's Microcomputer Lab.

Donna Peterson, an upper-level computer science major, was employed in June of 1983 to write a PASCAL program for an online record of student achievement; the program was implemented in September. When each assignment is turned in and graded, the record is modified to indicate whether or not the assignment was completed successfully and the date of completion or attempt. Each entry is made using an ID number, an assignment code (the initial letter of the title of the assignment) and the date of the entry. The date is placed in an appropriate column to designate whether the assignment was satisfactory or not. The record also indicates the grade the student is working towards and the final grade if no more assignments are submitted.

The Student Record is used to assign subjects for use with worksheets dealing with the Periodicals Department, the Documents Department and the Instructional Media Center. When a student first retrieves the student record, headings are chosen at random from three lists and locked into the record. They appear each time the program is run under that student's ID number.

Student Records are updated several times each week and the program allows the instructor to add or delete students and to modify records at will. Due dates for assignments are entered at the beginning of the semester and listings of students who fail to submit assignments by given due dates are available throughout the semester. Also, the possible grade for the course is adjusted in the record of each student who fails to submit an assigment.

An interactive electronic mail system can be used to communicate with students. Using this program, the instructor can specify what is needed to complete assignments or ask students to come in for assistance.

Students are given handouts with step-by-step instructions for using terminals. The instructions provide for the use of video display terminals or DECwriters, if hardcopy is desired. Terminals are available in a number of locations, including the library and each of the dorms.

Handouts for LMED 100 are prepared using an IBM Personal Computer, Easywriter and an Adler electronic typewriter. Although slow, the Adler produces letter-quality masters for duplication. Unfortunately, this system has not proven dependable. A few students own microcomputers such as the Commodore and an attempt is being made to develop software to allow them to access the mainframe and retrieve LMED 100 lessons from offcampus. 